\title{
Techno-Economic Analysis of PAYG Productive Uses of Energy in Malawi
}

Kyle Smith, Aran Eales, Damien Frame, Stuart Galloway University of Strathclyde,

Aran.eales@strath.ac.uk

GHTC, Seattle, October 2019 


\section{Overview}

- Context:

- Energy Access in Malawi

- PUE Theory of Change

- Methodology

- Feasibility Studies

- Piloting

- Results

- Conclusions 


\section{(2) SUSTANADABE GOALS}

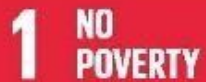

mititid

7

7

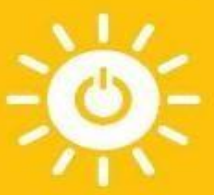

18

Holve

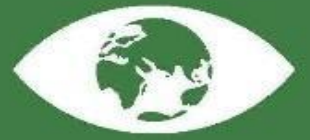

a) 2E:0

\& HUNGER

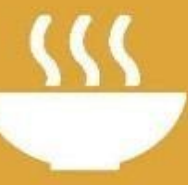

- DEEENT WOR AND

EBONOWGGROWII

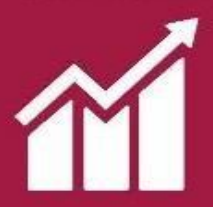

4. LFE

4 BELOW WAIER

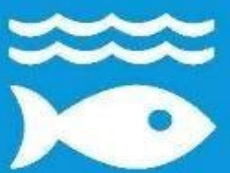

9 GODD HEALTH

c ANDWELLEENG

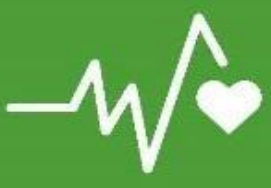

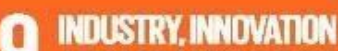

- ADILRASTRL

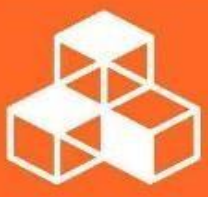

14 LIFE

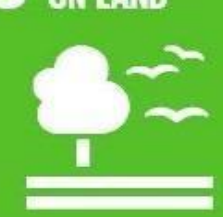

4 QUALITY

4 EDUCATION

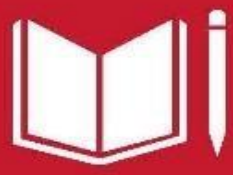

(A) REDIIEEI

INEOUALITIES

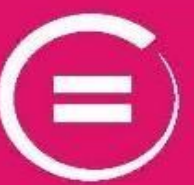

R PEABE, JUSTIBE

ANDSTRONG INSTITUTIONS

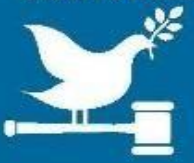

G GENDER
EOUALITY

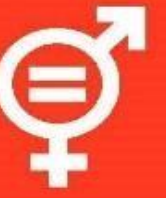

44 SISTALABIE GIIISS AWD 60 WIITIISS

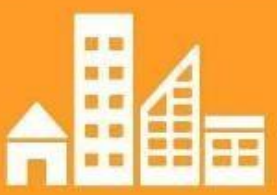

4T PARTNERSYIPS FOR THE GOALS

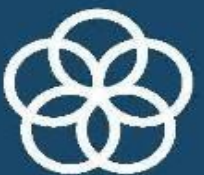

D BLANWATER

( ANDSANIIATION

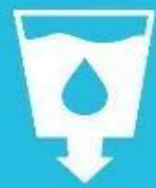

19 REPONSIE BONSIMPIION ANDPRODUEIOY

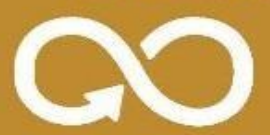

(79)

SUSTAINABLE DEVELOPMENT GALS

Sustainable energy powers education and health systems, new businesses in previously unserved communities, jobs, manufacturing and industrialization, and water storage and food security. 


\section{Context: Energy Access in Malawi}

- Energy access is an enabling factor for human development (UNDP)

- Access to national electricity grid in Malawi is currently just $9.8 \%$ (SE4All, 2016)

Malawi

Electricity Profile

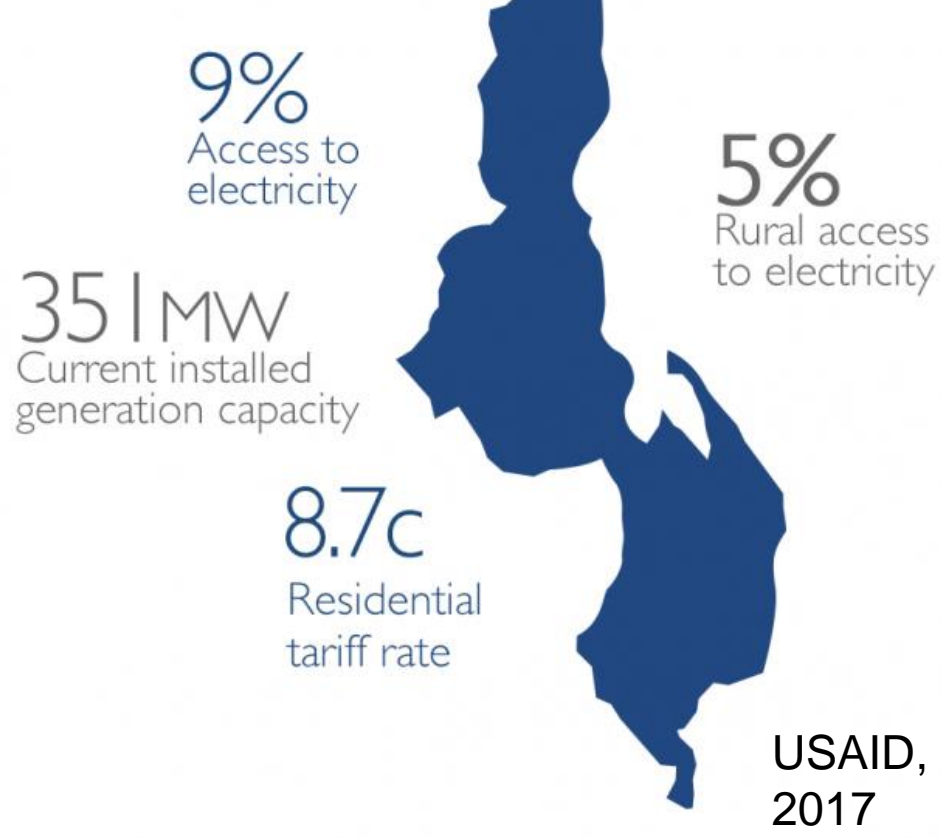

- Donor funded nationwide initiatives

- 13.6 million people live off-grid in Malawi

- Lighting needs served by kerosene, candles and nonrechargeable batteries.

- The Malawi National Energy Policy contains policies to tackle the challenges to increase energy access in a low carbon manner 


\section{Snapshot: Dedza District}

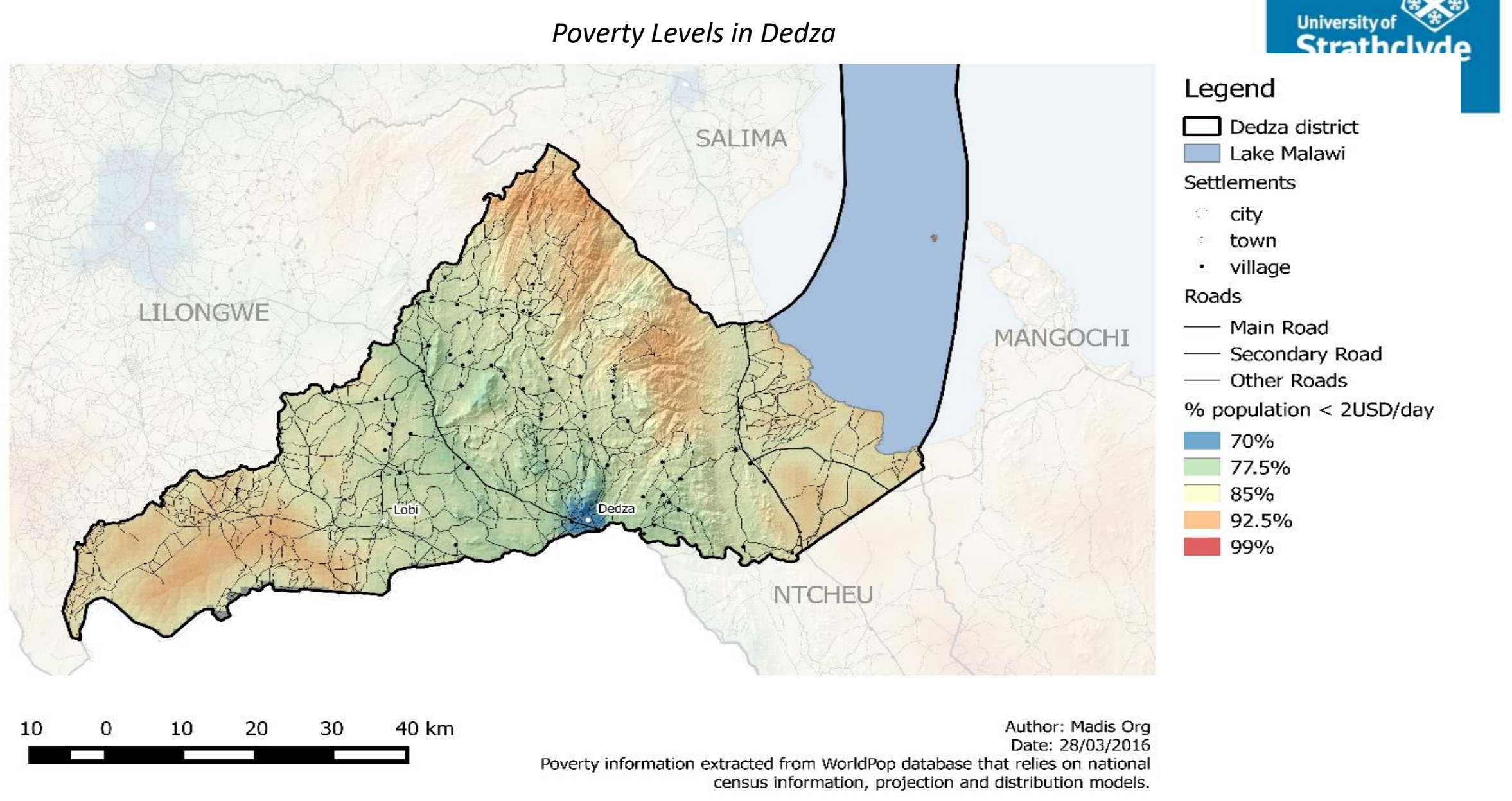

- Poverty levels range between $70 \%$ - $99 \%$ of the population living under $\$ 2 /$ day

- Low life expectancy (45.4 yrs) and very high fertility rate (5.8 children).

- Main challenges affecting communities in Dedza include lack of capital to start businesses, drinking water, infrastructure, and availability/affordability of agricultural inputs. 


\section{Productive Use of Solar PV}

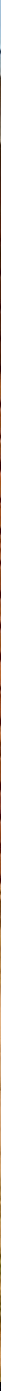

"Agricultural, commercial and industrial activities involving energy services as a direct input to the production of goods or provision of services." 


\section{PUE: Theory of Change}

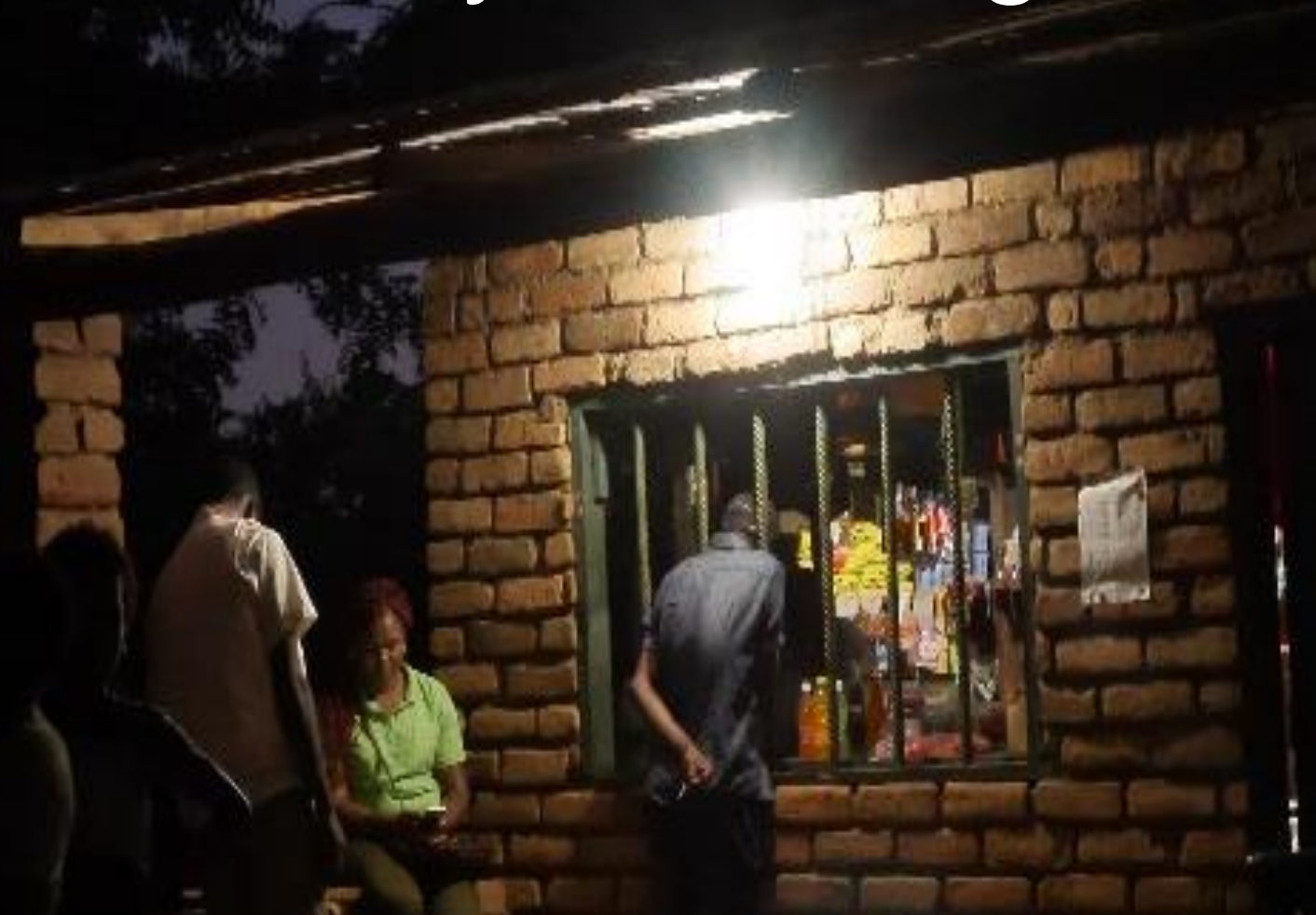

Energy
Supply
(adequate
quality and
quantity)

Changes in enterprise: productivity, cost of production, prices, product volumes, operating hours, employment
Poverty Reduction use; adoption of appliances
Generation of income or GDP, other benefits (comfort of operation) 


\section{Methodology}
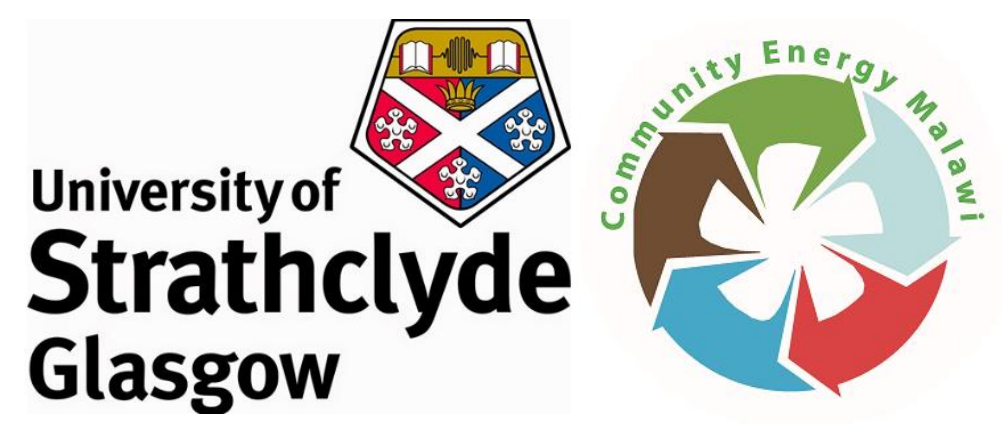

Feasibility Studies

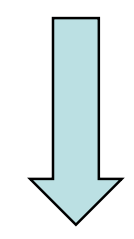

Pilot Projects

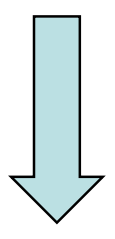

Recommendations

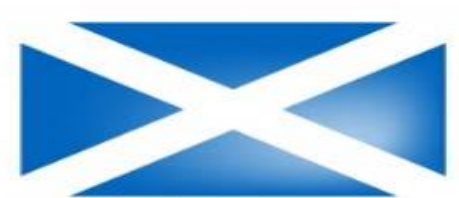

The Scottish Government Riaghaltas na h-Alba

- Fieldwork conducted by University of Strathclyde and Community Energy Malawi in Dedza District, Malawi, 2017-2018

- Funding from Scottish Government through ongoing Decentralised Energy Access research and implementation programme 


\section{PUE Feasibility Studies: Primary Data Collection}

\section{Existing}

electricity using

business

surveys

- CAPEX, OPEX, Income

- Load Profiles

- Socio-economic data

Off-grid household surveys
Focus Group Discussions
- Perception and Awareness

- Multi Criteria Scoring

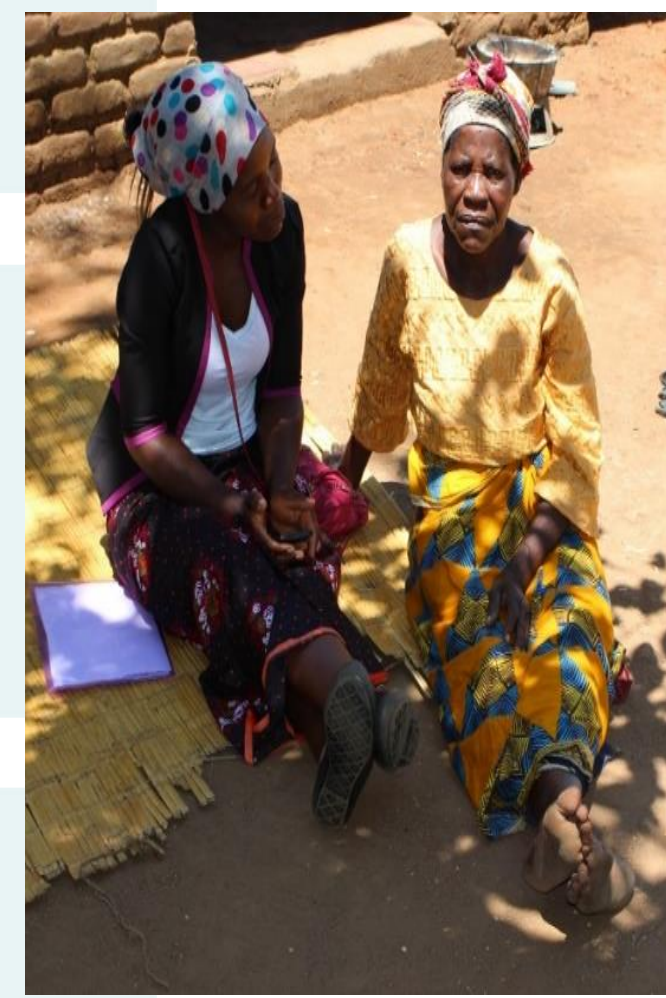




\section{PUE System Design and Business Modelling}

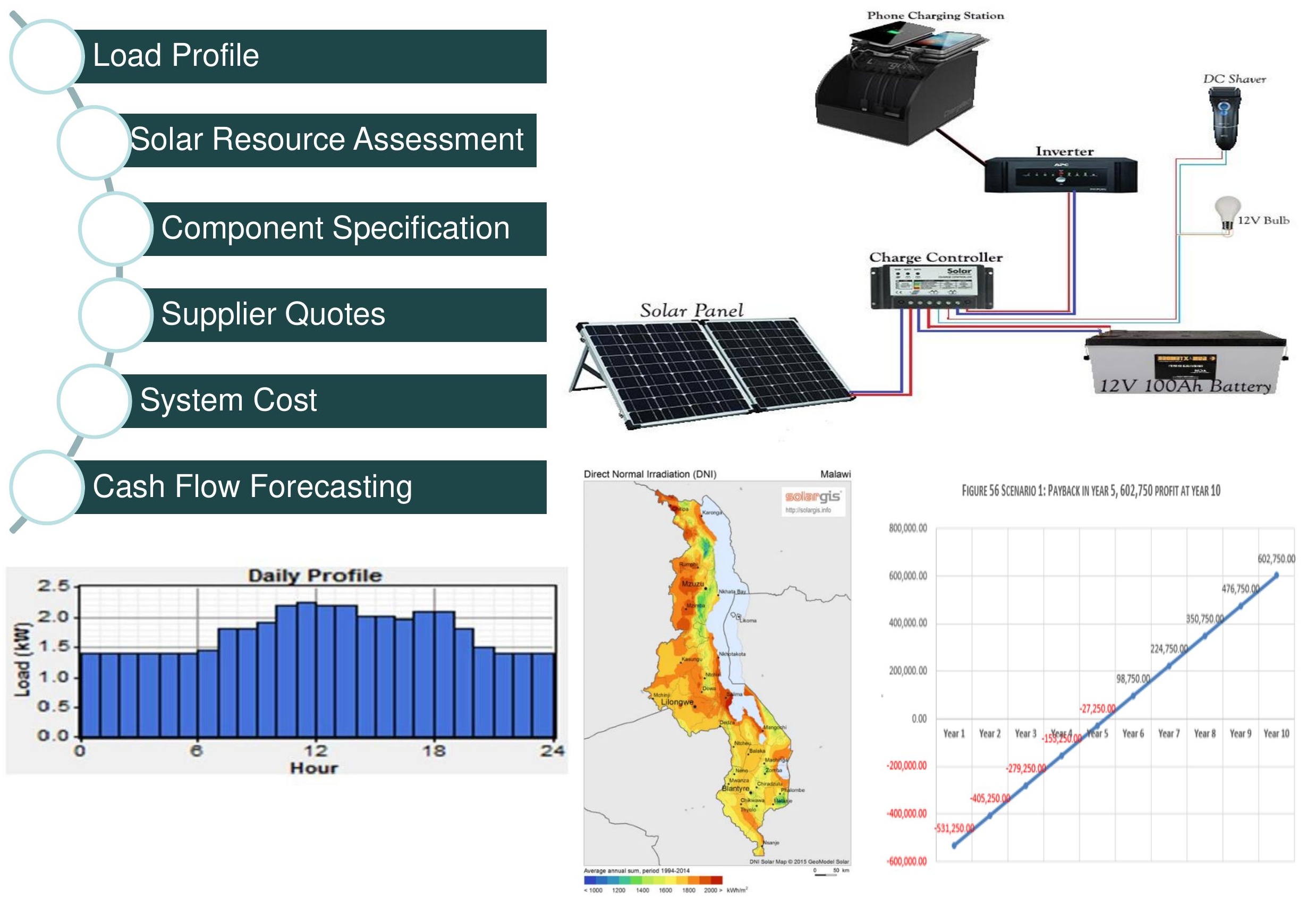




\section{Feasibility Results: Business Desirability}

Ranked businesses from the "pick 5, 3 and 1" Question

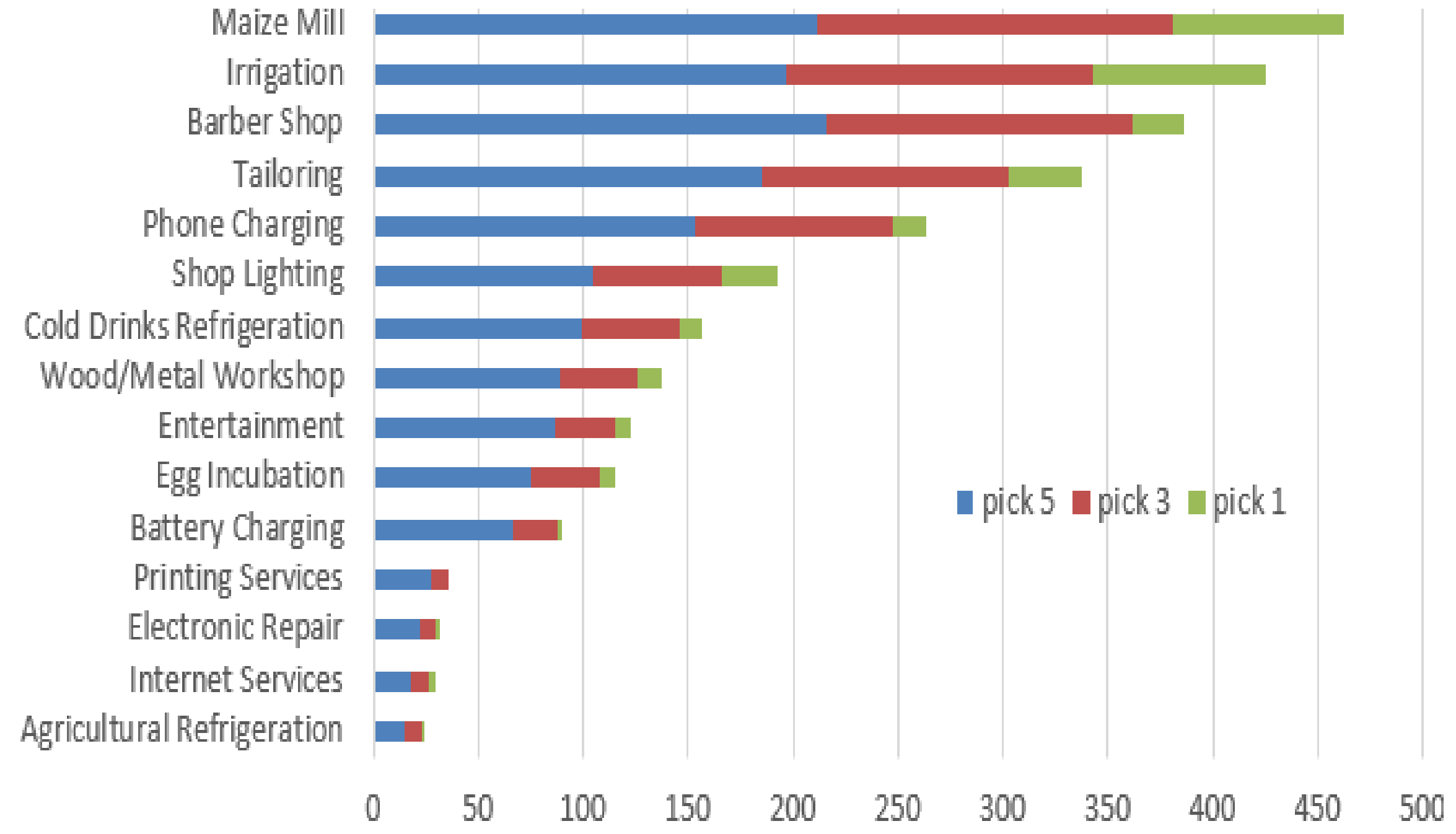




\section{Feasibility Results: Cash Flow Forecast}

\begin{tabular}{|c|c|c|c|c|c|c|c|}
\hline & \multicolumn{2}{|c|}{ Scenario 1 } & \multicolumn{2}{c|}{ Scenario 2 } & \multicolumn{2}{c|}{ Scenario 3 } & Viability \\
\hline Businesses & $\begin{array}{c}\text { Payback } \\
\text { (years) }\end{array}$ & $\begin{array}{c}10 \text { year } \\
\text { profit }\end{array}$ & $\begin{array}{c}\text { Payback } \\
\text { (years) }\end{array}$ & $\begin{array}{c}10 \text { year } \\
\text { profit }\end{array}$ & $\begin{array}{c}\text { Payback } \\
\text { (years) }\end{array}$ & $\begin{array}{c}10 \text { year } \\
\text { profit }\end{array}$ & \\
\hline Irrigation & 2 & $\$ 8,552$ & 3 & $\$ 7,711$ & 5 & $\$ 17,902$ & HIGH \\
\hline $\begin{array}{c}\text { Barbershop } \\
\text { and Phone } \\
\text { Charging }\end{array}$ & 2 & $\$ 2,762$ & 2 & $\$ 1,851$ & $>10$ & 0 & HIGH \\
\hline \begin{tabular}{c} 
Maize mill \\
\hline Tailoring
\end{tabular} & 5 & $\$ 6,896$ & 8 & $\$ 2,135$ & $>10$ & 0 & MEDIUM \\
\hline $\begin{array}{c}\text { Metal } \\
\text { workshops }\end{array}$ & $>10$ & 0 & $>10$ & 0 & $>10$ & 0 & MEDIUM \\
\hline
\end{tabular}




\section{Pilot Projects: Pay As You Go Business Enerqy (PAYGO-BE)}

- Local entrepreneurs receive a PUE PV system and agree to pay-back the cost of the system over a period of time.

- Piloted in Dedza, logging electrical demand and income/expenditure
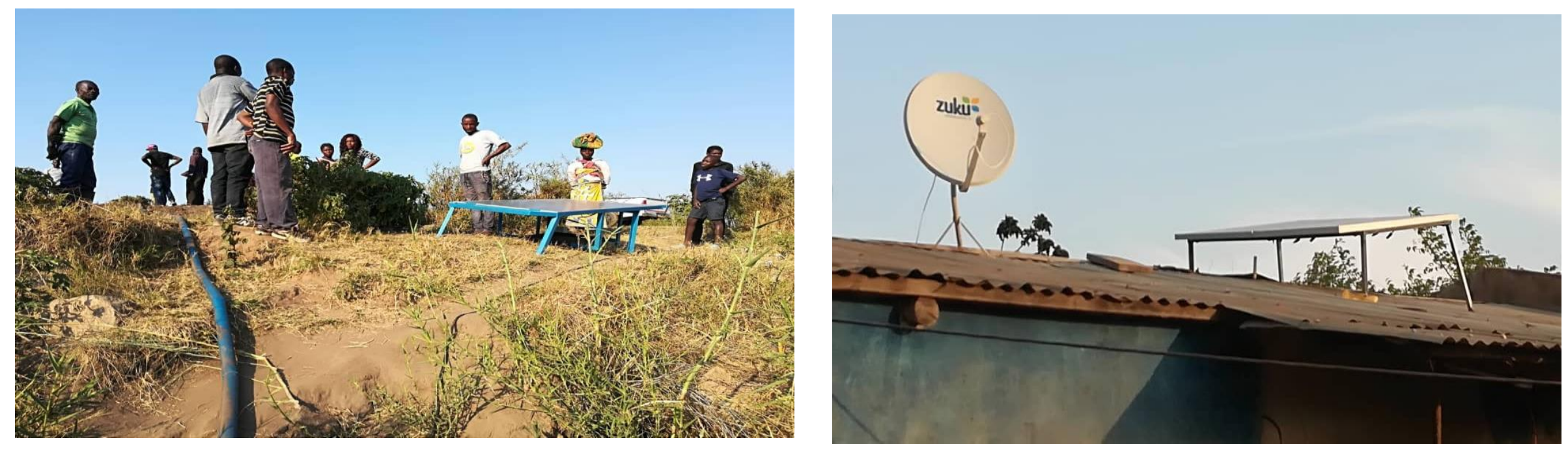

\begin{tabular}{|l|c|c|c|c|}
\hline \multicolumn{1}{|c|}{ Product } & Deposit & $\begin{array}{c}\text { Loan } \\
\text { Amount }\end{array}$ & $\begin{array}{c}\text { Monthly } \\
\text { Payment }\end{array}$ & $\begin{array}{c}\text { Term } \\
\text { (months) }\end{array}$ \\
\hline Refrigeration & $\$ 63$ & $\$ 2,414$ & $\$ 49$ & 36 \\
\hline $\begin{array}{l}\text { Barber \& Phone } \\
\text { Charging }\end{array}$ & $\$ 21$ & $\$ 605$ & $\$ 34$ & 18 \\
\hline Shop Lighting & $\$ 13$ & $\$ 227$ & $\$ 13$ & 18 \\
\hline Irrigation & $\$ 56$ & $\$ 2,268$ & $\$ 63$ & 36 \\
\hline TV show & $\$ 42$ & $\$ 1,837$ & $\$ 49$ & 36 \\
\hline
\end{tabular}

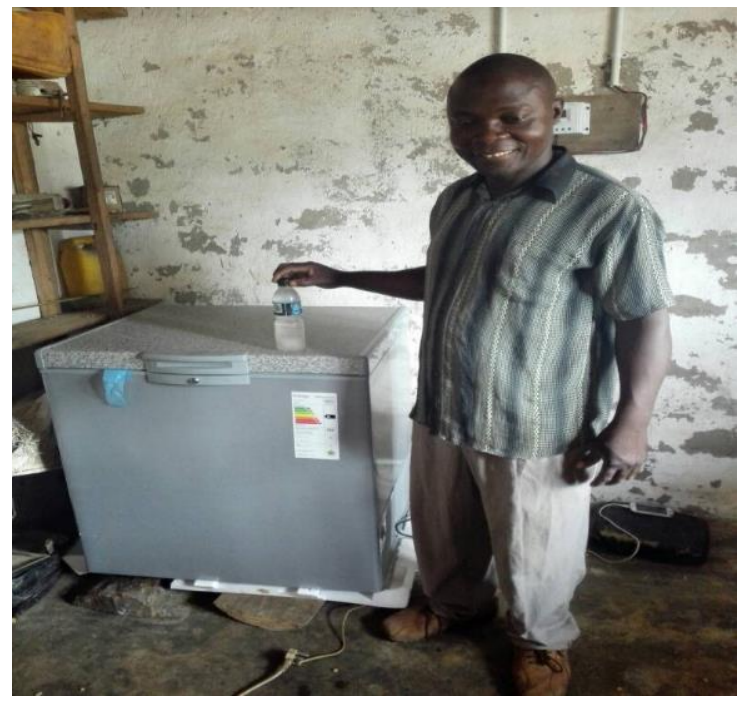




\section{Pilot Projects: System Specifications}

\section{Barbershop \& Phone Charging}

- Solar PV: 100W, Batteries: 192Ah, Inverter: 10A

- Appliances: Hair clippers, phone chargers, bulbs, and sound system

- Total cost to customer: $432,000 \mathrm{MKW}$

\section{Shop Lighting}

- Solar PV: 10W, Batteries: 3Ah, Inverter: NA

- Appliances: Radio, cables for charging phones, 4 LED lights, torch

- Total cost to customer: $162,000 \mathrm{MKW}$

Irrigation

- Solar PV 275W, Batteries: NA, Inverter: NA

- Appliances: Water pump

- Total cost to customer: $1,620,000 \mathrm{MKW}$

\section{Refrigeration}

- Solar PV: 200W, Batteries 400Ah, Inverter: Sine Wave and 6.8A

- Appliances: Fridge (DEFY), phone charger, bulbs

- Total cost to customer: 1, 724, $000 \mathrm{MKW}$

TV System

- Solar PV: 2 x 150W, Batteries: 2 x 150Ah, Inverter: 500W

- Appliances: TV, decoder, DVD

- Total cost to customer: 1, 312, $000 \mathrm{MKW}$ 


\section{Pilot Project Financial Results}

Barber Shop Financial Statement

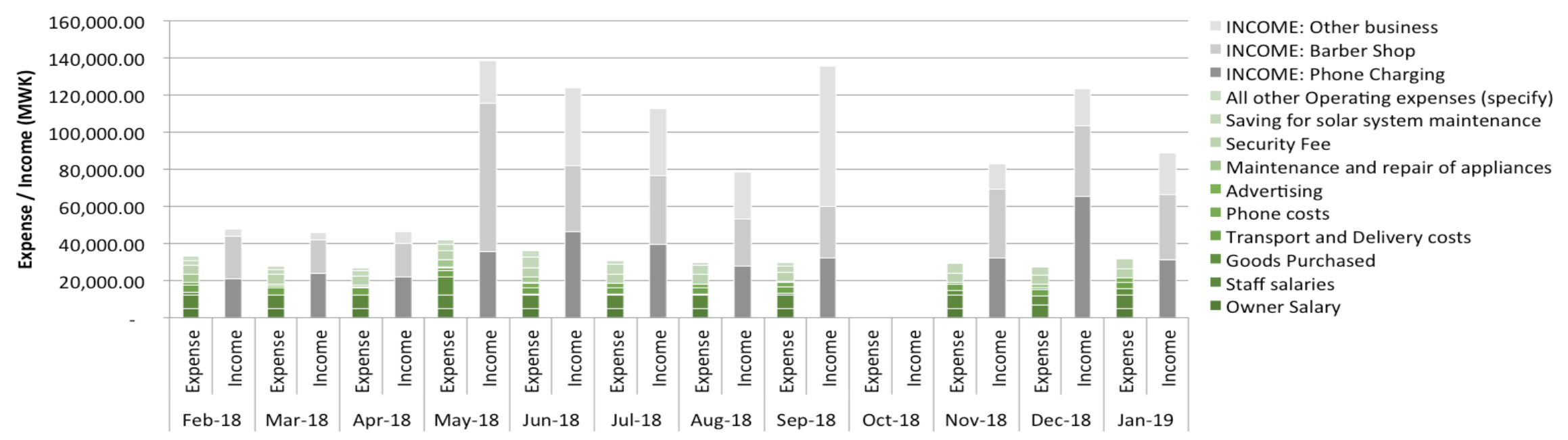

Refrigeration: Chilled Products \& Groceries

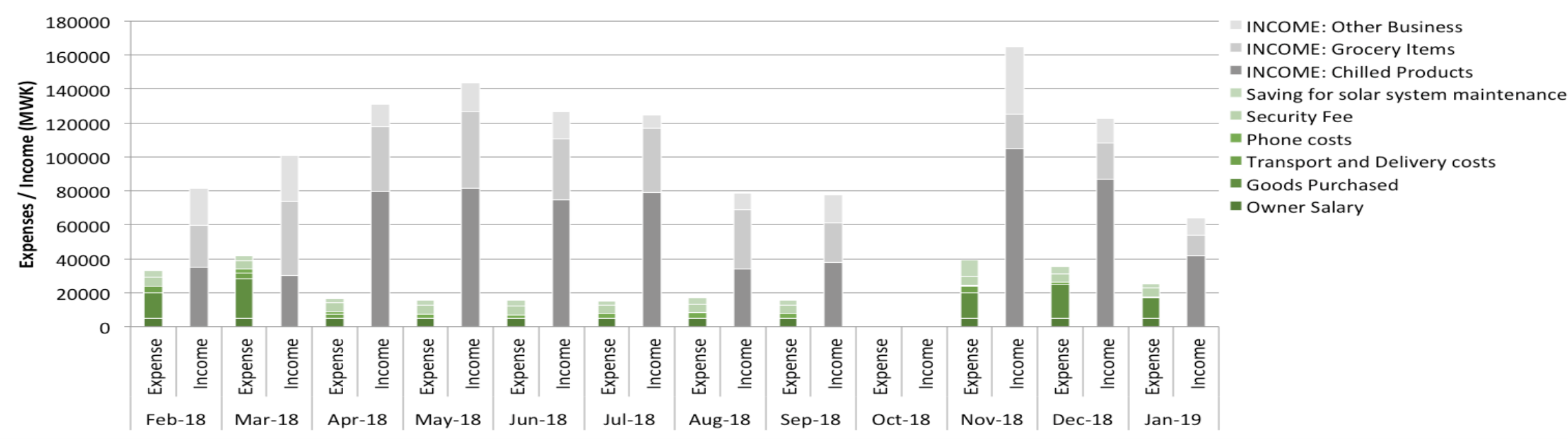

After twelve months of operating the PUE systems, all entrepreneurs stated that their business income has increased and that monthly repayments have not been a burden. 


\section{Barriers in the PUE Enabling Environment}

Capacity

Lack of entrepreneurship, management, accounting skills

Standards and Regulations

Lack of regulation of the Solar PV market causing an influx of cheap counterfeit products. Being addressed in part by the Malawi Bureau of Standards (MBS) and Malawi Energy Regulatory Authority (MERA)

Finance

Limited options, none ideal: Bank Loans, Microfinance, Village Savings and Loans Supply Chain

Availability of system components materials can be a limiting factor. Becoming more available in trading centres, with concerns over quality of the goods supplied.

Policy and Governmental support

Lack of clarity on national Energy Policy, no support for energy at district level.

Availability and Affordability of Energy

Even competitive innovations can remain unaffordable to the majority in emerging markets. PV Maintenance costs prohibitive for smaller businesses 


\section{Conclusions}

- Methodologies for assessing PUE feasibility in Malawi have been presented which can be adapted to use in other scenarios.

- There is a commercial case for PAYG-BE customers but this must be implemented at scale (>100 installations are required).

- The long-term sustainability of the PAYG-BE case requires sufficient revenue to be generated that can support the central management and administration costs of the PUE provider. This can only be achieved if the current projects/solutions are deployed at scale

- Future PAYG-BE customers should use a mobile payment solution to collect the monthly payments rather than cash in-hand. This ensures transparency in reporting for both sides (the PUE provider and the local entrepreneur).

- The development of this business case must also demonstrate an accurate and transparent financial reporting process for the issuing of loans and collection of loan payments.

- Barriers in the enabling environment need to be tackled to promote scale up 


\title{
Thanks for listening
}

\author{
aran.eales@strath.ac.uk
}

